\title{
Use of Crude Glycerol for Glycerolysis of Free Fatty Acids in Crude Palm Oil
}

\author{
Nanda Suriaini ${ }^{1}$, Normalina Arpi², Yanna Syamsuddin³ ${ }^{3}$ Muhammad Dani Supardan ${ }^{3 *}$ \\ ${ }^{1}$ Doctoral School of Engineering, Universitas Syiah Kuala, Jalan Tengku Syech Abdur Rauf No. 7, Darussalam, \\ Banda Aceh 23111, Indonesia \\ ${ }^{2}$ Department of Agricultural Product Technology, Universitas Syiah Kuala, Jalan Tgk. Hasan Krueng Kalee \\ No.3, Darussalam, Banda Aceh 23111, Indonesia \\ ${ }^{3}$ Department of Chemical Engineering, Universitas Syiah Kuala, Jalan Tengku Syech Abdur Rauf No. 7, \\ Darussalam, Banda Aceh 23111, Indonesia
}

\begin{abstract}
The glycerolysis of crude palm oil (CPO) using potassium hydroxide was studied. This work aimed to evaluate free fatty acid (FFA) conversion in CPO through glycerolysis using crude glycerol. The effect of molar ratios of FFA to crude glycerol, reaction temperature, stirring speed, and catalyst loading was investigated. The best conditions for the highest FFA conversion of $95.45 \%$ were found: 1:4 of FFA to crude glycerol molar ratio, $75^{\circ} \mathrm{C}$ of reaction temperature, $250 \mathrm{rpm}$ stirring speed, and $0.75 \%(\mathrm{w} / \mathrm{w}$ of oil) of catalyst loading. These conditions have decreased the FFA of CPO from $6.15 \%$ to $0.28 \%$ in 90 minutes. A kinetic model of the second-order reaction rate was used to quantify the influence of process parameters. It can be concluded that the crude glycerol as a side product of transesterification can be utilized in glycerolysis to lower the cost of biodiesel production.
\end{abstract}

Keywords: Crude glycerol; Crude palm oil; Free fatty acid; Glycerolysis

\section{Introduction}

The increasing demand for fuel as an energy source is a challenge due to the depletion of petroleum reserves. Another aspect that has become a concern in recent years is pollution using fossil fuels, which causes global warming-an increase in the earth's temperature. Biodiesel-fatty acid alkyl esters-is a renewable, non-toxic, and biodegradable fuel that can replace petroleum diesel fuel (Ibrahim et al., 2020). Biodiesel has some advantages compared to petroleum diesel, such as renewable, clean-burning fuels, and biodegradable ones that produce fewer toxic pollutants and greenhouse gasses (Hidayat et al., 2018; Amin, 2019).

Several methods have been developed to produce biodiesel, such as esterification, transesterification, pyrolysis, supercritical reaction, and lipase-catalyzed (Kottititum et al., 2014). The most common method is transesterification. In this method, the vegetable oil reacts with an alcohol (e.g., methanol or ethanol) in the presence of an alkaline catalyst to produce biodiesel and glycerol as a by-product. Transesterification is considered more efficient and can produce biodiesel with a high yield and purity. However, this process requires high purity oil as a raw material. Oil as a raw material for transesterification 
reaction should contain $\mathrm{FFA}<0.5 \%$ or acid number $<1 \mathrm{mg} \mathrm{KOH} / \mathrm{g}$ (Kara et al., 2018). The presence of FFA in oil can cause side reactions through alkaline-catalyzed transesterification to form soaps and prohibit ester product and glycerol separation. As a result, the quantity and quality of biodiesel obtained will be reduced if it does not use an appropriate production process (Aparamarta et al., 2019). Esterification is generally the initial treatment of raw materials with high FFA content and is carried out before transesterification. However, esterification requires relatively high temperatures, large amounts of alcohol, and acid catalysts. Berrios et al. (2010) used a molar ratio up to 1:60 of FFA to methanol to reduce the FFA of waste cooking oil from $2.14 \%$ to $0.34 \%$.

Glycerolysis is an alternative method that can be carried out to reduce FFA content in oil as biodiesel feedstock before the transesterification reaction. This process is usually applied when FFA content is higher than 5\% (Mamtani et al., 2021). Additionally, glycerolysis is more profitable as no excessive amount of methanol is used during the process like in acid esterification (Elgharbawy et al., 2021). Glycerolysis is considered as a potential method because the use of glycerol as a byproduct of transesterification process; therefore, it is expected to reduce the price of biodiesel production (Supardan et al., 2017).

Wang et al. (2011) reported the application of a superacid solid catalyst for the glycerolysis of FFA in waste cooking oil. However, the use of superacid solid catalysts has several disadvantages, such as high catalyst prices, excess glycerol needs, catalyst separation difficulties, and high reaction temperatures. Many studies reported that base catalysts could be used to speed up a glycerolysis reaction. Kombe et al. (2013) and Kombe (2015) have examined the use of $\mathrm{NaOH}$ base catalysts for glycerolysis of castor and jatropha oils. Based on their research, the FFA content can be reduced from $4.54 \%$ and $6.50 \%$ to $0.07 \%$ and $0.06 \%$, with temperatures of $65^{\circ} \mathrm{C}$ and $56^{\circ} \mathrm{C}$, respectively. Supardan et al. (2017) used co-solvent to enhance the mass transfer in glycerolysis of waste cooking oil. Recently, the intensification of the glycerolysis reaction using hydrodynamic cavitation was reported by Satriana et al. (2018).

Currently, crude palm oil (CPO) is the major vegetable oil source for biodiesel production in Indonesia. However, the FFA content in CPO is relatively sensitive to the environment. There is potential for the utilization of CPO with high FFA to lower biodiesel production cost. In this work, CPO with high FFA content reacted with crude glycerol as a low-cost reactant obtained from transesterification using a base catalyst. This research is expected to contribute to the development of the biodiesel manufacturing process. The objective of this work was to evaluate the effect of crude glycerol to FFA molar ratio, reaction temperature, stirring speed, and catalyst loading on the performance of the glycerolysis process. The effect of process parameters is quantified through the study of glycerolysis kinetics.

\section{Methods}

\subsection{Materials}

Crude palm oil was procured from Nagan Raya District, Aceh, Indonesia. It was stored and maintained in normal laboratory conditions. The initial acidity of CPO was $13.47 \mathrm{mg}$ $\mathrm{KOH} / \mathrm{g}$, which was equivalent to $6.15 \%$ FFA. Meanwhile, the crude glycerol was obtained from the side-product of the transesterification reaction. Analytical grade phosphoric acid 85\% and potassium hydroxide 99\% were purchased from Merck (Darmstadt, Germany).

\subsection{Experimental Procedures}

Firstly, CPO was degummed with phosphoric acid 1.5\% (v/v of oil) at temperatures $65-70^{\circ} \mathrm{C}$ for 15 minutes. After the degumming process, CPO was transferred into a 
separating funnel to separate the gum from the oil. Then, CPO from the upper layer was moved to a centrifuge for the complete separation process.

A $500 \mathrm{ml}$ three-neck round-bottom flask assembled with adjustable speed magnetic stirrer, condenser, and thermometer was used to carry out the glycerolysis reaction. The prescribed amount of catalyst $\mathrm{KOH}$ and crude glycerol was added to the flask and stirred to form a potassium glycerolic solution. The CPO was heated on a hotplate. Then, the solution was mixed with CPO and maintained at a specified reaction condition. Samples were taken from the flask every 5 minutes for the first 15 minutes and a 15-minute interval until terminated after 90 minutes. The influence of the molar ratio of FFA to crude glycerol, reaction temperature, stirring speed, and catalyst loading were studied. Figure 1 illustrates the schematic of the experimental apparatus used in this study.

The progress of glycerolysis reaction at different experimental conditions has been monitored in terms of FFA conversion. The acid-base titration technique was used, and conversion calculated based on the change in the acid number of the sample. The conversion of FFA (X) can be calculated using Equation 1.

$$
\mathrm{X}(\%)=\frac{[\mathrm{FFA}]_{0}-[\mathrm{FFA}]_{\mathrm{t}}}{[\mathrm{FFA}]_{0}} \times 100
$$

where $[\mathrm{FFA}]_{\mathrm{t}}$ is the concentration of FFA at time $\mathrm{t}(\mathrm{mg} \mathrm{KOH} / \mathrm{g})$ and $[\mathrm{FFA}]_{0}$ is the initial concentration of FFA (mg KOH/g).

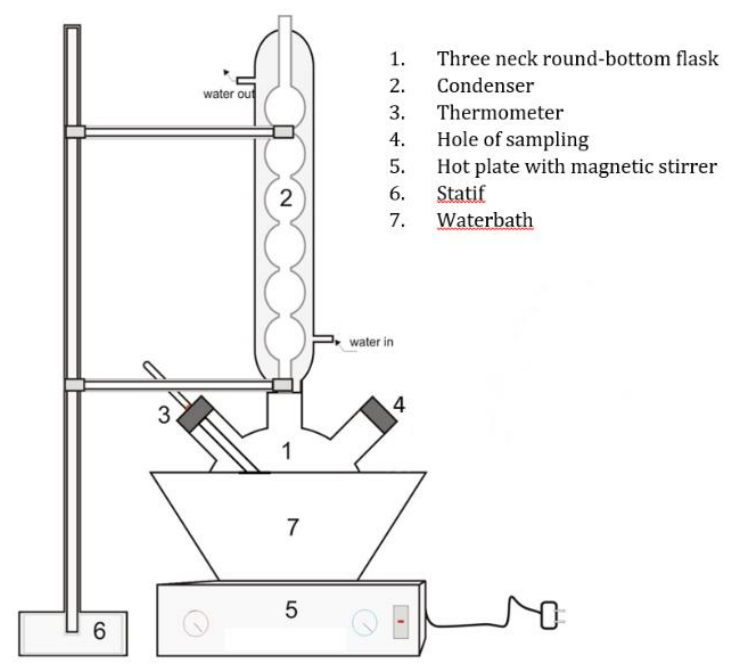

Figure 1 Experimental setup

\section{Results and Discussion}

\subsection{Effect of Process Parameters}

The rate of glycerolysis reaction has been evaluated by varying the molar ratios of FFA to crude glycerol at $1: 2,1: 3,1: 4$, and $1: 5$. The reaction temperature $65^{\circ} \mathrm{C}$, catalyst loading $0.75 \%$ (w/w of oil), and stirring speed $250 \mathrm{rpm}$ were kept constant. As shown in Figure 2, the FFA conversion increased significantly in the first 15 minutes of the reaction time. The conversion was constant after 30 minutes of the reaction time. During the first 15 minutes of reaction time, Supardan et al. (2017) previously observed a similar result for glycerolysis reaction of waste cooking oil. At the end of the 90-minutes reaction time, the conversion of FFA was found dependent on the process parameters.

Experimental results showed that the excess of crude glycerol would increase the conversion of FFA. Kombe et al. (2013) reported a similar trend of result. Conversion of FFA 
reached $93.02 \%$ at molar ratio FFA to crude glycerol 1:4, the highest value compared to the other molar ratio. Figure 2 showed that a further increase in the molar ratio of crude glycerol to $4: 1$ seems ineffective for enhancing the FFA conversion. According to the reaction stoichiometry, the molar ratio of FFA to glycerol needed to run the glycerolysis reaction is 3:1. The conversion of FFA is affected by reaction displacement to product formation by increasing the molar ratio of FFA to glycerol beyond the stoichiometry value. However, the excess of one of the reactants can push the reaction forward to a certain extent only (Mamtani et al., 2021). As previously reported by Kumoro (2012), glycerol could enhance the interaction of intermicellar and flexibility, which would be necessary when a solvent is present in the reaction medium. Kombe et al. (2013) reported a similar result for glycerolysis of jatropha oil, where the glycerol to oil ratio of $2.24 \mathrm{~g} / \mathrm{g}$ gives a reaction efficiency of $98.67 \%$ at $65^{\circ} \mathrm{C}$ temperature and 73 minutes for reaction time, respectively.

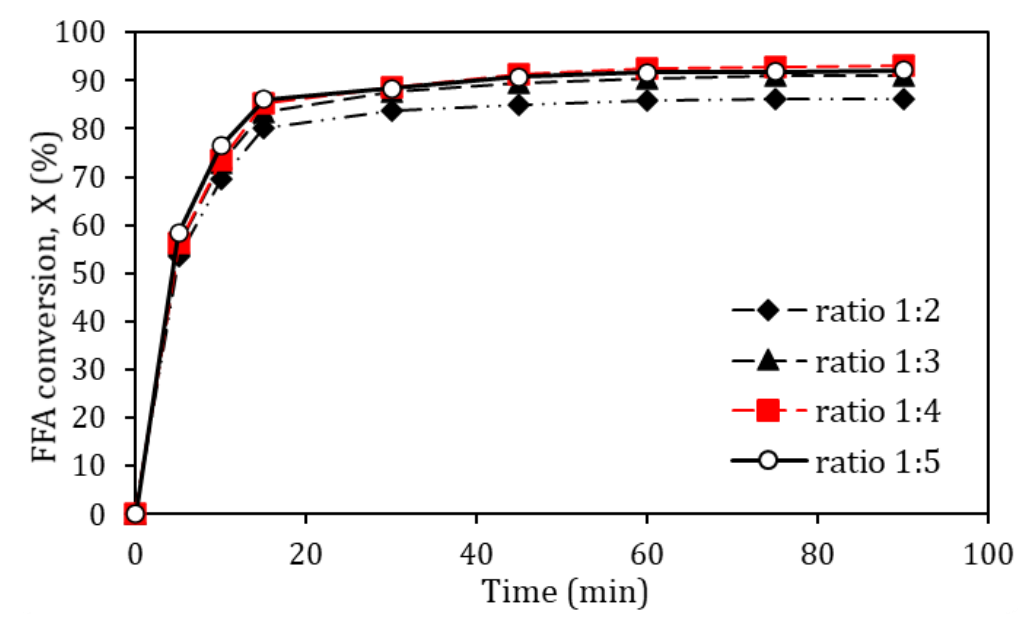

Figure 2 Effect of FFA to crude glycerol molar ratio on FFA conversion

Some authors have studied the glycerolysis reaction with acidic catalysts as a pretreatment method for lowering high FFA. However, acid-catalyzed glycerolysis was carried out at a temperature above $120^{\circ} \mathrm{C}$ for more than 120 minutes of reaction time (Kumoro, 2012; Gole and Gogate, 2014; Supardan et al., 2017). Kumoro (2012) inferred that alkaline catalyst is more effective for glycerolysis at low temperatures. It can be seen in Figure 3; the conversion of FFA increased when the temperature increased from $55^{\circ} \mathrm{C}$ to $85^{\circ} \mathrm{C}$. The maximum FFA conversion of $95.45 \%$ was obtained at $75^{\circ} \mathrm{C}$ with the kept condition at $1: 4$ of FFA to crude glycerol and $250 \mathrm{rpm}$ of stirring speed.

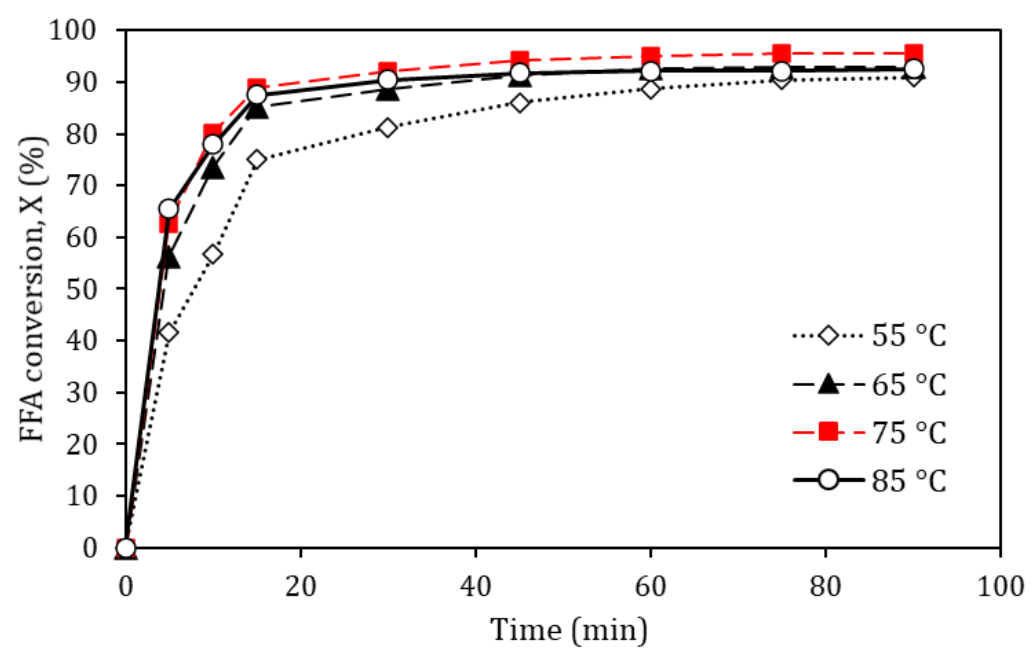

Figure 3 Effect of temperature on FFA conversion 
Figure 3 implied that a higher temperature made the optimum conversion of FFA possible within a shorter reaction time. The experimental result showed that at 15 minutes of reaction time, the FFA conversion increased from $75.06 \%$ to $88.82 \%$ when the reaction temperature increased from $55^{\circ} \mathrm{C}$ to $75^{\circ} \mathrm{C}$. Kombe et al. (2013) found that glycerolysis can be operating at a low temperature, but it takes a longer time to achieve a high conversion. This was the result of increasing reaction temperature which will increase mass transfer and increase reactants' solubility (Saha and Goud, 2015). However, a further increase in reaction temperature to $85^{\circ} \mathrm{C}$ did not provide additional benefits because the reaction temperature had passed alcohol's boiling point.

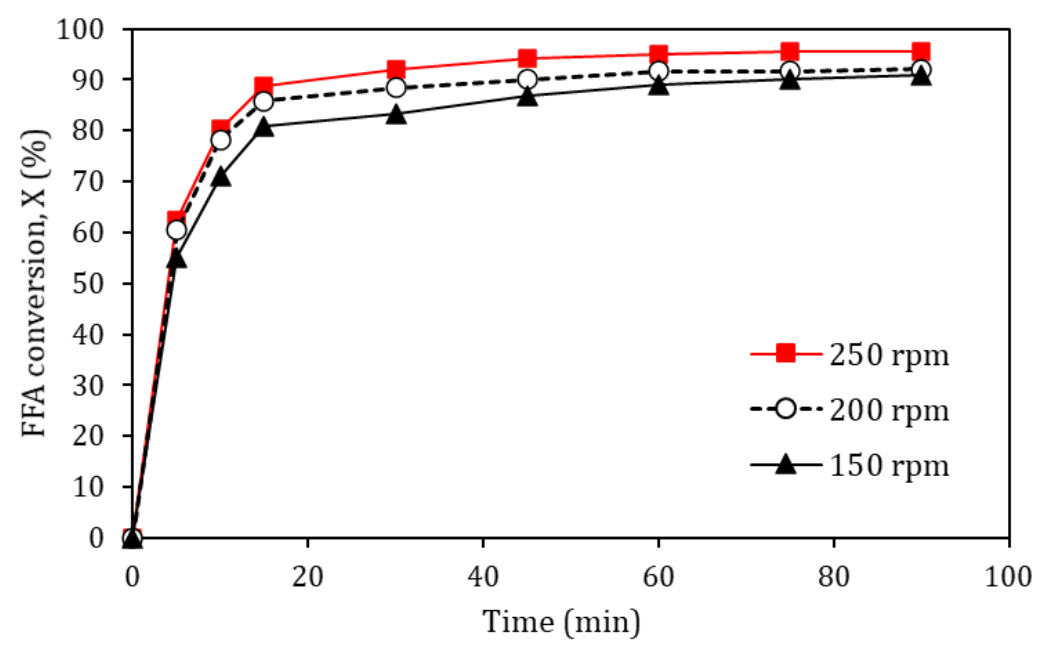

Figure 4 Effect of stirring speeds on FFA conversion

The effect of stirring speeds on the conversion of FFA contained in CPO is presented in Figure 4. The FFA conversion increased significantly up to 15 minutes of reaction time and was followed by a slight increase up to 90 minutes of reaction time. Speed of $250 \mathrm{rpm}$ has resulted in the highest conversion of $95.45 \%$ at 90 minutes reaction time. Stirring can improve mass transfer by promoting the molecular mobility of reactants. It could then create a better contact between the reactants to increase the reaction conversion (Kumoro, 2012). However, the stirring speed's further effects could not be observed due to the limitation of the experimental equipment.

Glycerolyzed CPO with high FFA content was influenced by the amount of catalyst loading, although the reaction can occur without the addition catalyst (Gole and Gogate, 2014). The catalyst used was $\mathrm{KOH}$ because it is cheap, stable, and soluble in glycerol. Additionally, $\mathrm{KOH}$ has a very strong activity in extraction of hydrogen atoms from the hydroxyl groups of alcohols, such as methanol and glycerol (Elgharbawy et al., 2021). The FFA conversion against the reaction time has been investigated for catalyst loading from 0.5 to $1 \%$ by weight of oil (Figure 5 ). The increase in the conversion of FFA with the increase in catalyst loading from 0 to $0.75 \%$ can be attributed to the fact that the catalyst works by increasing the total number of available active catalytic sites. However, the conversion of FFA lowered to about $90 \%$ at catalyst concentration 1\%. Mohod et al. (2017) also observed that the addition of catalyst exceeds 2\%; not many favorable results were obtained due to enhanced catalyst loading for Karanja oil esterification. The best FFA conversion was $95.45 \%$ by using $\mathrm{KOH} 0.75 \%$. As a comparison, the conversion of the uncatalyzed reaction achieved $56.02 \%$ within 90 minutes of reaction time. It is essential to determine the optimum catalyst loading because it is closely related to the process's economics, especially when the catalyst price is high. Furthermore, the excess of catalyst loading enhances the duty on the separation steps. 


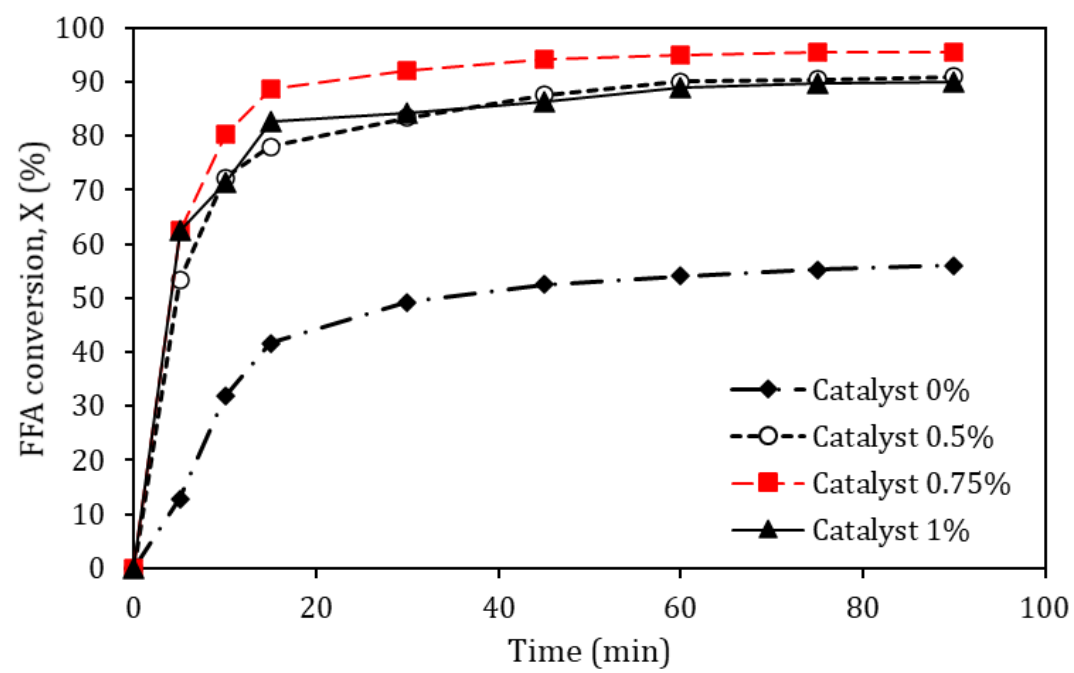

Figure 5 Effect of catalyst loading on FFA conversion

Verification of CPO, crude glycerol, and glycerolyzed CPO were carried out using FTIR spectroscopy. Spectrums from the sample can verify the relevant functional group of the materials (Bahadi et al., 2016; Diao et al., 2017). The FTIR spectra of CPO, crude glycerol, and glycerolyzed CPO were depicted in Figure 6.

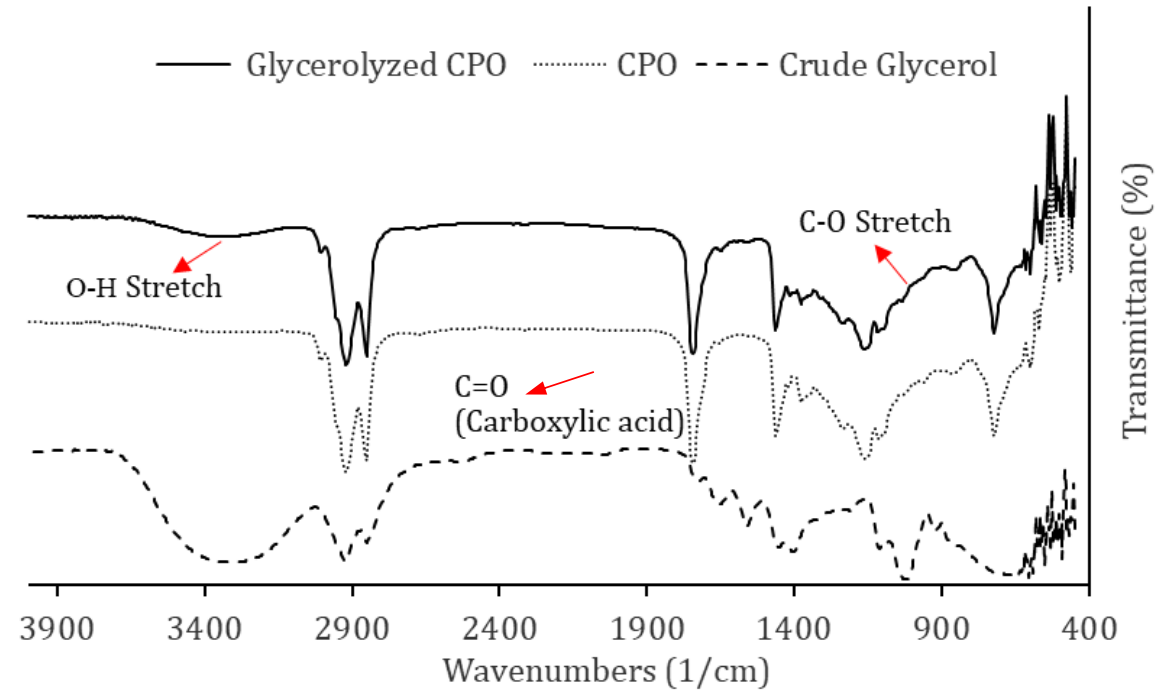

Figure 6 FTIR spectra of CPO, glycerolyzed CPO, and crude glycerol

The prominent absorption bands from three types of samples appeared to be similar. The main functional groups and corresponding wavenumbers were as follows: $\sim 3006 \mathrm{~cm}^{-}$ 1 for bending of $\mathrm{C}=\mathrm{C}, \sim 2920$ and $\sim 2850 \mathrm{~cm}^{-1}$ for symmetrical and asymmetrical stretching of $-\mathrm{CH}_{2}, \sim 1743 \mathrm{~cm}^{-1}$ for stretching $\mathrm{C}=0, \sim 1462 \mathrm{~cm}^{-1}$ for bending (scissoring) of $-\mathrm{CH}_{2}, \sim 1161$ $\mathrm{cm}^{-1}$ for stretching of $\mathrm{C}-0$, and $\sim 721 \mathrm{~cm}^{-1}$ for swing vibration of $-\left(\mathrm{CH}_{2}\right)_{4}$ (Lerma-García et al., 2010; Fattah et al., 2014). These groups existed in CPO and glycerolyzed CPO. The broad peak at $\sim 3321 \mathrm{~cm}^{-1}$ is assigned to intermolecular hydrogen $(-\mathrm{OH})$ stretching vibration that existed in crude glycerol and glycerolyzed CPO (Maulida et al., 2020). Furthermore, the FTIR spectrum of glycerolyzed CPO presented a slightly lower peak area of absorption bands than crude glycerol at $\sim 3399 \mathrm{~cm}^{-1}$. Figure 6 also showed $\mathrm{C}=0$ for the spectrum of ester and carboxylic acid at $\sim 1743$ and $\sim 1713 \mathrm{~cm}^{-1}$, respectively. However, the peak of carboxylic acid $\mathrm{C}=0$ relatively dissipated in the spectrum of glycerolyzed $\mathrm{CPO}$. It was proven that the process is effective for reducing FFA in CPO (Bahadi et al., 2016). The peak at 1037 
$\mathrm{cm}^{-1}$ indicated $\mathrm{C}-\mathrm{O}$ stretch because glycerolyzed CPO contained an alcohol group. These results presented that the glycerolysis process did not change the components of CPO. Besides, the glycerolysis process did not produce undesirable substances (Diao et al., 2017).

\subsection{Kinetic Study}

The glycerolysis mechanism is normally defined by three consecutive reactions. Triacylglyceride (TAG) is the main product, and monoacylglyceride (MAG) and diacylglyceride (DAG) are the intermediate products-along with water-that formed as a by-product. The steps of reaction can be presented by the following mechanism (Tu et al., 2017):

$$
\begin{gathered}
G+F F A \leftrightarrow M A G+\mathrm{H}_{2} \mathrm{O} \\
M A G+F F A \leftrightarrow D A G+\mathrm{H}_{2} \mathrm{O} \\
D A G+F F A \leftrightarrow T A G+\mathrm{H}_{2} \mathrm{O}
\end{gathered}
$$

The overall reaction between glycerol $(\mathrm{G})$ and FFA can be expressed as:

$$
\mathrm{G}+3 \mathrm{FFA} \leftrightarrow \mathrm{TAG}+3 \mathrm{H}_{2} \mathrm{O}
$$

The kinetics model used the following assumptions: (i) the rate of non-catalyzed reaction was negligible to the catalyzed reaction; (ii) glycerolysis reaction took place in the oil phase; and (iii) the rate for backward direction was negligible relative to the forward direction. Based on these assumptions, the glycerolysis reaction can be represented by the secondorder reaction in the forward direction. The kinetics of glycerolysis have been studied concerning the concentration FFA as a function of time. Therefore, the reaction rate can be expressed by Equation 6 .

$$
\frac{d[T G]}{d t}=-\frac{d[F F A]}{d t}=k[G][F F A]
$$

Assuming that the concentration of both reactants was the same, Equation 6 can be modified as:

$$
\begin{gathered}
-\frac{d[F F A]}{d t}=k \cdot[F F A]^{2} \\
-\int_{F F A}^{F F A} \frac{d[F F A]}{F F A}=k \int_{0}^{t} d t \\
{\left[\frac{1}{[F F A]}-\frac{1}{\left[F F A_{0}\right]}\right]=k \cdot t} \\
\frac{1}{[F F A]}=\frac{1}{\left[F F A_{0}\right]}+k \cdot t
\end{gathered}
$$

The reaction rate constant $(k)$ can be estimated based on the decrease of FFA during the reaction by plotting 1/[FFA] as a function of time. Equation 8 fitted the experimental data quite well with coefficient of linear correlation $\left(R^{2}\right)$ was higher than 0.80 . Table 1 presents the values of $k$ obtained from all of the experimental runs. As expected, the values of $k$ represent the effect of process parameters on the reaction rate. For example, the values of $k$ increased with increasing temperature. However, further temperature enhancements can also decrease the value of $k$. The reaction rate constant fell from 0.0212 to 0.0131 $\mathrm{L} / \mathrm{mol}$.min with an increase in reaction temperature from 75 to $85^{\circ} \mathrm{C}$. Moreover, ethanol's boiling point is below $85^{\circ} \mathrm{C}$, so under this condition, ethanol started vaporizing, which would reduce the reaction rate.

The influence of reaction temperature on the reaction rate was obtained by fitting the $k$ value to the Arrhenius equation,

$$
\begin{array}{r}
k=A \cdot e^{\left[\frac{-E a}{R T}\right]} \\
\ln k=-\frac{E a}{R} \cdot \frac{1}{T}+\ln A
\end{array}
$$


Table 1 Values of the constant rate $k$

\begin{tabular}{|c|c|c|}
\hline Experimental runs & $k(\mathrm{~L} / \mathrm{mol} . \mathrm{min})$ & Reaction condition \\
\hline \multicolumn{3}{|c|}{ FFA/crude glycerol variation } \\
\hline $1: 2$ & 0.0068 & \multirow{4}{*}{$\begin{array}{c}\mathrm{T}: 65^{\circ} \mathrm{C}, \\
\text { stirring: } 250 \mathrm{rpm} \text {, catalyst } \\
0.75 \% \mathrm{w} / \mathrm{w}\end{array}$} \\
\hline $1: 3$ & 0.0105 & \\
\hline $1: 4$ & 0.0136 & \\
\hline $1: 5$ & 0.0121 & \\
\hline \multicolumn{3}{|l|}{ Temperature variation } \\
\hline $55^{\circ} \mathrm{C}$ & 0.0092 & \multirow{4}{*}{$\begin{array}{c}\text { FFA/crude glycerol:1/4, } \\
\text { stirring: } 250 \mathrm{rpm}, \\
\text { catalyst: } 0.75 \% \mathrm{w} / \mathrm{w}\end{array}$} \\
\hline $65^{\circ} \mathrm{C}$ & 0.0136 & \\
\hline $75^{\circ} \mathrm{C}$ & 0.0212 & \\
\hline $85^{\circ} \mathrm{C}$ & 0.0131 & \\
\hline \multicolumn{3}{|l|}{ Stirring speed variation } \\
\hline $150 \mathrm{rpm}$ & 0.0094 & \multirow{3}{*}{$\begin{array}{c}\text { FFA/crude glycerol: } 1 / 4, \\
\text { T: } 75^{\circ} \mathrm{C}, \\
\text { catalyst: } 0.75 \% \mathrm{w} / \mathrm{w}\end{array}$} \\
\hline $200 \mathrm{rpm}$ & 0.0119 & \\
\hline $250 \mathrm{rpm}$ & 0.0212 & \\
\hline \multicolumn{3}{|l|}{ Catalyst loading variation } \\
\hline $0 \%$ & 0.0013 & \multirow{4}{*}{$\begin{array}{c}\text { FFA/crude glycerol:1/4, } \\
\text { T: } 75^{\circ} \mathrm{C}, \\
\text { stirring: } 250 \mathrm{rpm}\end{array}$} \\
\hline $0.5 \%$ & 0.0098 & \\
\hline $0.75 \%$ & 0.0212 & \\
\hline $1.0 \%$ & 0.0090 & \\
\hline
\end{tabular}

Using the plots of ln $k$ as a function of the reciprocal temperature, then, both the activation energy, $E a$, and pre-exponential factor, $A$, were obtained from the equation of linear regression. Calculated Arrhenius activation energy and pre-exponential factors are listed in Table 2.

Table 2 Estimated Arrhenius parameters

\begin{tabular}{lcc}
\hline Parameters & Unit & Value \\
\hline Intercept & - & -4332.3 \\
Slope & - & 8.411 \\
$R^{2}$ & - & 0.973 \\
$E a$ & (kcal/mol) & 8.608 \\
$A$ & (L/mol.min) & $4,495.355$ \\
\hline
\end{tabular}

The activation energy obtained is in agreement with the previously reported information by Noureddini and Zhu (1997). As compared with the values reported by Kumoro (2012), the activation energy of this study was slightly different from the value with catalysis by sodium hydroxide using glycerol $(99 \% \mathrm{w} / \mathrm{w})(5.485 \mathrm{kcal} / \mathrm{mol})$. It is possibly due to the role of isopropyl alcohol as a solvent to raise the solubility of glycerol-tryglyceride, so it might help to bring down the energy activation. Also, the kinetic work by Kumoro (2012) reviews the reaction between TG and G to produce MG and DG, whereas, in this study, it is the reaction between $\mathrm{G}$ and FFA to form TG and $\mathrm{H}_{2} \mathrm{O}$.

\section{Conclusions}

In the present study, free fatty acid in CPO was reduced through glycerolysis using crude glycerol. The base catalyst, $\mathrm{KOH}$, can efficiently catalyze glycerolysis of FFA in CPO using crude glycerol. In the range of experiments studied, the initial FFA of $6.15 \%$ was reduced to $0.28 \%$ under the following conditions: $1: 4$ of FFA to crude glycerol molar ratio, $75^{\circ} \mathrm{C}$ of reaction temperature, $250 \mathrm{rpm}$ of stirring speed, and $0.75 \% \mathrm{w} / \mathrm{w}$ of catalyst loading. Therefore, glycerolysis is potential to be applied because it would decrease the FFA 
in $\mathrm{CPO}$ to be lower than $0.5 \%$ as biodiesel feedstock for a transesterification reaction. The kinetic study showed that the second-order reaction rate could be used to describe the glycerolysis reaction. It can be concluded that the utilization of crude glycerol as a byproduct of transesterification for reducing the cost of biodiesel production has the potential to be implemented. However, there is still a need to develop an intensification process for glycerolysis to lower the temperature and enhance the immiscibility of oil and glycerol phases.

\section{Acknowledgements}

We would like to acknowledge the contributions of Universitas Syiah Kuala, which has funded this research through Program Riset Unggulan Universitas Syiah Kuala Percepatan Doktor (PRUU-PD) research grant No. 292/UN11/SPK/PNBP/2020.

\section{References}

Amin, A., 2019. Review of Diesel Production from Renewable Resources: Catalysis, process kinetics and technologies. Ain Shams Engineering Journal, Volume 10(4), pp. 821-839

Aparamarta, H.W., Gunawan, S., Azhar, B., Aditya, H.T., Widjaja, A., Ju, Y.H., 2019. Comparative Study of Batchwise Solvent Extraction and the Microwave Assisted Extraction Method for the Purification of Triglyceride for Biodiesel Feedstock from Crude Calophyllum Inophyllum Oil (CCIO). International Journal of Technology, Volume 10(3), pp. 551-560

Bahadi, M.A., Japir, A., Salih, N., Salimon, J., 2016. Free Fatty Acids Separation from Malaysian High Free Fatty Acid Crude Palm Oil Using Molecular Distillation. Malaysian Journal of Analytical Sciences, Volume 20(5), pp. 1042-1051

Berrios, M., Martín, M.A., Chica, A.F., Martín, A., 2010. Study of Esterification and Transesterification in Biodiesel Production from Used Frying Oils in a Closed System. Chemical Engineering Journal, Volume 160(2), pp. 473-479

Diao, X., Guan, H., Kong, B., Zhao, X., 2017. Preparation of Diacylglycerol from Lard by Enzymatic Glycerolysis and Its Compositional Characteristics. Korean Journal for Food Science of Animal Resources, Volume 37(6), pp. 813-822

Elgharbawy, A.S., Sadik, W.A., Sadek, O.M., Kasaby, M.A., 2021. Glycerolysis Treatment to Enhance Biodiesel Production from Low-quality Feedstocks. Fuel, Volume 284, https://doi.org/10.1016/j.fuel.2020.118970

Fattah, R.A., Mostafa, N.A., Mahmoud, M.S., Abdelmoez, W., 2014. Recovery of Oil and Free Fatty Acids from Spent Bleaching Earth using Sub-critical Water Technology Supported with Kinetic and Thermodynamic Study. Advances in Bioscience and Biotechnology, Volume 5(3), pp. 261-272

Gole, V.L., Gogate, P.R., 2014. Intensification of Glycerolysis Reaction of Higher Free Fatty Acid Containing Sustainable Feedstock Using Microwave Irradiation. Fuel Processing Technology, Volume 118, pp. 110-116

Hidayat, A., Mukti, N.I.F., Handoko, B., Sutrisno, B., 2018. Biodiesel Production from Rice Bran Oil over Modified Natural Zeolite Catalyst. International Journal of Technology, Volume 9(2), pp. 400-411

Ibrahim, H., Silitonga, A.S., Rahmawaty, Dharma, S., Sebayang, A.H., Khairil, Sumartono, Sutrisno, J., Razak. A., 2020. An Ultrasound Assisted Transesterification to Optimize Biodiesel Production from Rice Bran Oil. International Journal of Technology, Volume 11(2), pp. 225-234

Kara, K., Ouanji, F., Lotfi, E.M., Mhahi, M.E., Kacimi, M., Ziyad, M., 2018. Biodiesel Production 
from Waste Fish Oil with High Free Fatty Acid Content from Moroccan Fish-Processing Industries. Egyptian Journal of Petroleum, Volume 27(2), pp. 249-255

Kombe, G.G., 2015. Re-esterification of High Free Fatty Acid Oils for Biodiesel Production. Biofuels, Volume 6(1-2), pp. 31-36

Kombe, G.G., Temu, A.K., Rajabu, H.M., Mrema, G.D., Lee, K.T., 2013. Low Temperature Glycerolysis as a High FFA Pre-Treatment Method for Biodiesel Production. Advances in Chemical Engineering and Science, Volume 3(4), pp. 248-254

Kottititum, B., Chakton K., Srinophakun, T.R., 2014. Simulation Approach to Biodiesel Production from Palm Oil by Conventional and Reactive Distillation Processes. Kasetsart Journal (Natural Science), Volume 48, pp. 139-149

Kumoro, A.C., 2012. Experimental and Modeling Studies of the Reaction Kinetics of AlkalineCatalyzed Used Frying Oil Glycerolysis using Isopropyl Alcohol as a Reaction Solvent. Research Journal of Applied Sciences, Engineering and Technology, Volume 4(8), pp. 869-876

Lerma-García, M.J., Ramis-Ramos, G., Herrero-Martínez, J.M., Simó-Alfonso, E.F., 2010. Authentication of Extra Virgin Olive Oils by Fourier-Transform Infrared Spectroscopy. Food Chemistry, Volume 118(1), pp. 78-83

Mamtani, K., Shahbaz, K., Farid, M.M., 2021. Glycerolysis of Free Fatty Acids: A Review. Renewable and Sustainable Energy Reviews, Volume 137, https://doi.org/10.1016/j.rser.2020.110501

Maulida, A., Zahrati, Kamila, H., Mukhriza, T., Gani, A., Supardan, M.D., 2020. Intensification of Synthesis of Fatty Acid Isopropyl Ester using Microwave. International Journal of Technology, Volume 11(3), pp. 492-500

Mohod, A.V., Subudhi, A.S., Gogate, P.R., 2017. Intensification of Esterification of Non Edible Oil as Sustainable Feedstock using Cavitational Reactors. Ultrasonics Sonochemistry, Volume 36, pp. 309-318

Noureddini, H., Zhu, D., 1997. Kinetics of Transesterification of Soybean Oil. Journal of the American Oil Chemists' Society, Volume 74(11), pp. 1457-1463

Saha, R., Goud, V.V., 2015. Ultrasound Assisted Transesterification of High Free Fatty Acids Karanja Oil using Heterogeneous Base Catalysts. Biomass Conversion and Biorefinery, Volume 5(2), pp. 195-207

Satriana, Arpi, N., Supardan, M.D., Gustina, R.T., Mustapha, W.A.W., 2018. Low-temperature Glycerolysis of Avocado Oil. AIP Conference Proceedings, Volume 1940, https://doi.org/10.1063/1.5028015

Supardan, M.D., Fahrizal, Moulana, R., Safrida, D., Satriana, Mustapha, W.A.W., 2017. Effect of Co-Solvent Addition on Glycerolysis of Waste Cooking Oil. Pertanika Journal of Science and Technology, Volume 25(4), pp. 1203-1210

$\mathrm{Tu}$, Q., Lu, M., Knothe, G., 2017. Glycerolysis with Crude Glycerin as an Alternative Pretreatment for Biodiesel Production from Grease Trap Waste: Parametric Study and Energy Analysis. Journal of Cleaner Production, Volume 162, pp. 504-511

Wang, Y., Ma, S., Wang, L., Tang, S., Riley, W.W., Reaney, M.J.T., 2011. Solid Superacid Catalyzed Glycerol Esterification of Free Fatty Acids in Waste Cooking Oil for Biodiesel Production. European Journal of Lipid Science and Technology, Volume 114(3), pp. 315324 